\title{
Ecologia cognitiva na sociedade da informação
}

\author{
Leonardo Lazarte
}

Professor do Departamento de Matemática e Coordenador do Núcleo de Estudos da Sociedade da Informação da Universidade de Brasília. Formado em Matemática na Universidad Nacional de Cuyo, na Argentina, foi pesquisador em Modelos Matemáticos em Física Nuclear na Comisión Nacional de Energia Atómica, em Otimização na Universidade Federal do Rio de Janeiro, e em Representação do Conhecimento no Imperial College da Universidade de Londres. Foi coordenador na região Centro-Oeste da RNP no período de implantação da Internet no país. As principais áreas de interesse são atualmente os paradigmas cognitivos integradores e as aplicações educacionais das tecnologias da informação.

\section{Resumo}

Além da dimensão econômica e suas implicações, a Sociedade da Informação traz mudanças na forma em que interpretamos o mundo, impacta nosso ambiente interior e põe novos desafios a nossas relações sociais. O surgimento de novos modos de cognição, a busca de novos modos de vida vida interior -, e um foco humanista na interação entre a tecnologia e as necessidades sociais são algumas destas dimensões pouco exploradas.

\section{Palavras-chave}

Sociedade da Informação; Sobrecarga informativa; Humanismo; Reversibilidade; Transdisciplinariedade; Holismo; Educação; Inclusão; Exclusão.

\section{Cognitive ecology in the information society}

\author{
Abstract \\ Beyond the economical dimension and its consequences, \\ Information Society brings about changes to the way we \\ interpret the world, it impacts our inner environment and poses \\ new challenges to our social relations. The emergence of \\ alternative cognitive paths, the search for new ways of life - \\ inner life -, and a human focus on the interaction of \\ technologies and social needs, are some of those forgotten \\ dimensions.
}

\section{Keywords}

Information society; Information overload; Humanism; Reversibility; Transdisciplinarity; Holism; Education; Inclusion; Exclusion.

\section{OS REMENDOS NA ROUPA NOVA DO REI}

Usualmente, a "Sociedade da Informação" é identificada com um mundo em que a informação é a nova mercadoria, esta direção de mudança é inevitável, e sua abrangência é global.

Esta visão simplificada, este credo não questionado, não explicita as bases sobre as quais esta "nova realidade" é construída, nem os pressupostos que a constituem. Chamamos a atenção aqui para os paradigmas cognitivos sobre os quais a atual avalanche informacional é construída e para as alternativas que estão sendo esboçadas.

Definir o novo fenômeno por sua dimensão econômica determina, a priori, uma forma de ver o mundo que exclui ou relega a um lugar secundário outros aspectos da vida humana. Recuperamos para a reflexão a dimensão do indivíduo que procura uma vida plena compatível com um ambiente que informacionalmente se mostra tão insalubre quanto os piores distritos industriais há 150 anos. É o desafio de uma "ecologia informacional".

Apresentar como inevitável a necessidade de os membros da sociedade se adaptarem ao novo ambiente de manipulação e acesso à informação, mesmo que o seja, implica a preponderância da técnica sobre o ser humano. Questionamos esta visão, não nos opondo como neoludditas, mas invertendo a ordem, pensando em primeiro lugar no ser humano e seus problemas e, a partir daí, em como a tecnologia pode contribuir para resolvêlos. Tocamos esta questão especificamente no âmbito da educação.

\section{RECONHECIMENTOS}

A escolha de três tópicos, para contribuir com esta revista, que complementassem as dimensões mais freqüentemente abordadas da Sociedade da Informação teve como base o trabalho e a reflexão de diversos grupos, que foram o âmbito de maturação e identificação das idéias aqui apresentadas. Além do reconhecimento desta influência, sua menção aqui contribui a explicitar o contexto em que os tópicos são gerados e dentro do qual adquirem seu sentido. 
Em primeiro lugar, cronologicamente e em ordem de importância na formação dos conceitos e, principalmente, dos referenciais aqui expressos quanto à interpretação do mundo, do homem e da sociedade, devo mencionar o "Comitê Americano para Investigação de Temas e Modelos com Perspectivas de Futuro"* , sob a orientação do doutor Ramón Muñoz Soler. A solicitação de ministrar um curso de palestras sobre os modelos cognitivos das ciências físicas, para estudiosos de diversas áreas, incluindo físicos, levou-me ao reconhecimento da ponte que existe entre as diversas disciplinas em um momento histórico, alimentando-se de um substrato comum. Falávamos de uma das ciências mais racionais, na qual se evidenciavam os limites do racionalismo. Na mesma direção, o trabalho posterior com física nuclear me levaria à computação, daí à informática, o reducionismo em sua máxima expressão, zero ou um, e, hoje, aos sistemas de informação e conhecimento que se esforçam por extrapolar estes limites.

Um dos focos de trabalho do doutor Muñoz à época era a idéia de síntese, expressa em dois de seus livros ${ }^{1}$, e motivo de reflexão do Comitê. Foi a partir daí que comecei meu trabalho sobre a idéia da reversibilidade ${ }^{2}$ como elemento superador da fragmentação racionalista, conforme expandido a seguir.

A reflexão e o trabalho realizado pelos membros do Núcleo de Estudos da Sociedade da Informação ${ }^{3}$ contribuíram em boa medida para ampliar o panorama de alguns dos tópicos aqui apresentados. De especial relevância foram os palestrantes convidados para o Seminário promovido pelo Núcleo no primeiro semestre de $2000^{4}$, assim como os debates com os demais membros do Núcleo.

Finalmente, a motivação mais direta para o questionamento da visão economicista e a priorização do social estão relacionadas com a participação do autor no Grupo de Trabalho sobre Educação, que participou da elaboração do Livro Verde do programa para a Sociedade da Informação, do governo federal.

A sintonia de objetivos com Nelson Pretto e Vani Kenski, membros do GT de Educação, foi fundamental para levarmos as questões a seguir desenvolvidas como

\footnotetext{
* O "Comitê Americano para Investigação de Temas e Modelos com Perspectivas de Futuro" foi constituído pelo Dr. Muñoz Soler, a partir de Buenos Aires, envolvendo cientistas, filósofos, humanistas e religiosos de diversos países das Américas e da Europa. O Comitê teve seu período de maior atividade entre 1970 e 1980.
}

propostas para o Livro Verde. Quem estiver interessado nos documentos do GT, pode consultar o endereço do programa Sociedade da Informação ${ }^{5}$, ou o do GT ${ }^{6}$. Agradeço a Eduardo Tadao Takahashi, coordenador do programa, a oportunidade de contribuição do GT, mesmo que trazendo pontos de vista divergentes.

\section{O CONTEXTO}

Grande parte das pessoas de alguma forma inseridas no contexto da "sociedade globalizada", principalmente as classes governantes, empresariais e intelectuais, identificam a importância cada vez maior que o fluxo e a manipulação da informação tem na sociedade que lhes é mais diretamente acessível. As características decorrentes da identificação, armazenamento, processamento e acesso à informação determinam cada vez mais suas vidas, seus relacionamentos profissionais, a visão que têm da sociedade e como nela influenciam.

Esta percepção leva a identificar a "sociedade da informação" como estágio evolutivo inevitável, quando não desejável, da organização social dos grupos humanos. Isto, por sua vez, faz desejável, se não premente, uma resposta da sociedade, em seus diversos segmentos, de modo que esta reorganização se realize de forma adequada, evitando uma nova marginalização no novo contexto que se esboça.

A identificação da "sociedade da informação" principalmente por meio de suas características econômicas: mudanças nas relações de trabalho e na valorização relativa dos elementos da economia, privilegiando o domínio das tecnologias da informação, têm conseqüências nas políticas que são adotadas, tanto em nível governamental quanto em empresas e outras organizações sociais.

A importância de uma resposta adequada a estes desafios é inquestionável. A inserção mais eqüitativa nos mecanismos que geram e distribuem as riquezas em nível global é fundamental para evitar, ou pelo menos não acentuar, a exclusão e marginalização que têm caracterizado as relações entre países e entre classes econômicas.

Há, entretanto, diversos outros elementos subjacentes na mudança ora identificada como "sociedade da informação". Para identificá-los e resgatar sua importância relativa, apoiamo-nos no referencial do ser humano, em suas dimensões individuais e sociais, pessoais e transcendentes. 
Esta visão não se contrapõe aos esforços realizados nos âmbitos mais diretamente relacionados com a dimensão econômica da sociedade; o que propõe é uma complementação, restituindo à nossa atenção dimensões do ser humano que sabemos e intuímos fundamentais, mas que muitas vezes ficam abafadas pela primazia que o que parece mais imediato impõe.

\section{SOCIEDADE DA INFORMAÇÃO OU ECONOMIA DA INFORMAÇÃO?}

Provavelmente o livro de Yoneji Masuda, Sociedade da Informação ${ }^{7}$, de 1980, sintetiza o que a maioria entende atualmente como "Sociedade da Informação": uma sociedade em que o peso do sistema econômico produtivo é cada vez mais centrado no fator informação, assim como os sistemas sociais anteriores foram caracterizados como sociedade caçadora, sociedade agrícola e sociedade industrial*.

Esta característica social parece incontestável. Só que têm alguns pressupostos por trás que podem ser, no mínimo, ampliados.

Em primeiro lugar, a caracterização de uma sociedade por sua dimensão econômica já é uma escolha bastante redutora. Poderia ser objetado que esta caracterização não implica o desconhecimento de que a sociedade não se esgota em sua dimensão econômica, entretanto a realidade das grandes definições políticas globais mostra que, de fato, esta redução é feita todo dia. É "realista" quem se curva aos argumentos das pressões financeiras internacionais, é "utópico" quem argumenta pela priorização das necessidades sociais e humanas.

Um segundo aspecto que é relevante observar é que a concretização de determinadas realizações sociais nada mais é que o resultado de modos de ver o mundo, a sociedade e o ser humano. Neste sentido, a atual avalanche informativa é a conseqüência do desenvolvimento de um tipo de pensamento, racional, reducionista, que tem como limite e máximo logro a representação de toda informação, de todo conhecimento, na mínima unidade informativa, a mínima capacidade de distinguir entre o que é e o que não é, simbolizada no bit, que com seus dois possíveis valores captura uma forma de ver o mundo, a mínima unidade de discernimento.

\footnotetext{
* Masuda não limita sua análise à dimensão econômica, apontando também outras características que o futuro desenvolvimento das tecnologias de informação veio confirmar, como a tendência à globalização, a interação em redes e a potencialização sinergética dos esforços.
}

Por outro lado, a visão que, se explicitada, ainda hoje é considerada "utópica", a da interação cooperativa, ou pelo menos sinergética dos indivíduos e grupos em rede, incorpora-se na construção do ambiente informacional atual de forma indissociável, se bem que não totalmente assimilada e compreendida em todas suas implicações. Por exemplo, as análises atuais do fenômeno Internet dificilmente tocam o quanto o aspecto cooperativo ainda é essencial, mesmo depois da chegada de "gente grande" ao jogo, ou seja, mesmo depois do investimento de centenas de bilhões de dólares.

A própria interpretação do mundo centrada em sua dimensão econômica impede que esta seja adequadamente dimensionada, introduzindo em sua análise elementos tradicionalmente ausentes. Esta inadequação se evidencia com particular força na perplexidade do funcionamento do mercado de capitais ligado às empresas "ponto com", ora a vedete do mercado, ora o vilão de suas quedas.

Em essência, as acentuadas mudanças sociais agudizadas pelo ambiente das tecnologias da informação põem a descoberto uma característica das análises econômicas que muitos economistas prefeririam esconder dos leigos: não há "leis" na economia. O que há são convenções sociais, de valores, de interação, construídas, como os demais elementos que constituem uma sociedade, ao longo do tempo, como resultante de situações naturais, históricas, jogos de interesses etc.

Assim, fica, hoje, mais evidente que nunca, que a escolha dos parâmetros de interação econômica pode, sim, ser em grande medida adaptada a fins que transcendem o âmbito econômico, subordinando-se, por exemplo, a necessidades e interesses sociais centrados no ser humano e sua plena realização enquanto tal.

Por enquanto, esta dimensão ainda é a mais estudada e a que centra a maioria das atenções, desde o relatório pioneiro "Release 1.0", de Esther Dyson ${ }^{8}$, em 1994, até os inúmeros eventos destinados a promover ou estudar o comércio eletrônico atual e suas possibilidades futuras.

\section{FRAGMENTAÇÃO E INFORMAÇÃO}

A identificação e o acúmulo de informação têm origens remotas, assim como os princípios da interpretação racional, analítica, fragmentadora da realidade, para facilitar sua compreensão. Há, entretanto, um consenso em identificar a cultura clássica grega como o início da sistematização do método racional, retomado mais recentemente na Europa, em especial a partir de Descartes. 
O atual crescimento explosivo do fluxo de informação exige uma reavaliação dos mecanismos cognitivos do homem, reinterpretando também o significado de conceitos como a própria informação.

É tradicional em informática separar os conceitos de "dados" e de "informação", carregando esta última uma carga semântica mais rica, em geral, contextualizada. Em uma instância mais elaborada, principalmente na área de inteligência artificial, fala-se em "conhecimento" e, concomitantemente, representação, processamento e até geração (automática) do mesmo. Os avanços na formalização das atividades cognitivas põem ao mesmo tempo em evidência seus limites, lembrando outras dimensões da conginção, como a sabedoria, que parece escorrer como água por entre os dedos da racionalização? .

A busca da interpretação do mundo por meio da compreensão de seus fragmentos menores levou à interpretação dos objetos materiais a partir das substâncias que os compõem, a interpretar estas substâncias a partir dos átomos de seus elementos constitutivos, a interpretar estes átomos e, em conseqüência, o mundo físico todo, em função das partículas elementares, até o ponto em que a natureza se recusou a se enquadrar neste paradigma, confundindo o que era entendido como matéria com o que era entendido como energia, violando o claro princípio de que as coisas, afinal, estão em algum lugar, e mesmo o dogma de que ou as coisas são de uma forma, ou não o são. Obviamente não foi o mundo que se rebelou, mas uma forma de interpretá-lo que mostrou seus limites.

$\mathrm{Na}$ busca da interpretação dos elementos cognitivos, a prática da análise reducionista foi acompanhada pela teoria que formalizava esta forma de compreensão. $\mathrm{O}$ desenvolvimento da linguagem matemática, em suas diversas etapas históricas, nas diversas culturas, carrega consigo elementos-chave da interpretação racional: a formalização e a redução da realidade aos elementos formais, substituindo a experimentação pela manipulação simbólica.

A introdução de meios de comunicação em larga escala proporcionada pelas novas tecnologias - o telégrafo - fez com que a formalização ampliasse seu alcance tradicional, procurando abranger informação em qualquer área. Estes esforços procuram, por um lado, identificar o que seria informação e, por outro, como codificá-la. A redução de experiências, idéias e conceitos iniciada com a conquista da linguagem falada, passando depois pelo caracteres ideográficos e mais recentemente pelos fonéticos, é reduzida, com o telégrafo, a ponto e traço, um ou zero. Em
1948, Claude E. Shannon ${ }^{10}$, matemático e aluno do pioneiro das políticas de informação, Vannevar Bush, estabelece as bases formais do que viria a ser a Teoria da Informação: o estudo dos limites da atomização no mundo da informação.

Pelo lado da computação, à mesma época, a digitalização, ou redução de toda informação (e computação) a zeros e uns, é plasmada nos trabalhos de Alan Turing (máquina de Turing), John von Neuman (máquina de von Neuman) e Norbert Wiener (Cibernética) ${ }^{11}$, entre outros.

Voltemos para o conceito intuitivo, operacional, que a maioria das pessoas tem de informação. Se prestarmos atenção, a informação só tem sentido, só é relevante para nós, se ajudar na tomada de decisões. Peço informação para pegar o ônibus certo. A disponibilidade de informação me permite escolher o melhor preço de um artigo, ou o melhor candidato em uma eleição. Milhares de livros em uma língua que não entendo, ou sobre um assunto que não me interessa, são a mesma coisa que nada; não se constituem em fonte de informação para mim.

A primeira limitação que se faz evidente no mundo do processamento da informação é a questão do contexto. Informação só tem valor dentro de um certo contexto. E a conseqüência lógica, mais informação, nem sempre é melhor. Ambas questões têm conseqüências que podem ser mais exploradas; a questão do contexto é chave nos mecanismos de representação e manipulação do conhecimento, na área de inteligência artificial; a questão de informação e quantidade nos leva a um outro ponto chave no processo cognitivo: a capacidade de ignorar.

Se os primeiros elementos do processo cognitivo estão relacionados com saber reconhecer, este reconhecimento só acontece porque simultaneamente sabemos ignorar o que não é relevante. De fato, desde os primeiros momentos de nossa vida, a identificação do cheiro ou da voz maternas é complementada com a capacidade de ignorar milhares de outros cheiros, de outros sons. Da mesma forma, os sons das palavras proferidas por diversas pessoas são sempre diferentes entre si. No processo de aprendizagem da linguagem, aprendemos a ignorar as diferenças de timbre, de entoação e outras, para identificar as palavras que elas representam, independentemente de quem as diga. 


\section{ECOLOGIA INFORMACIONAL}

O desequilíbrio neste novo ambiente informacional se manifesta de várias formas. Em primeiro lugar, a mais visível, o excesso de informação, que supera a capacidade do indivíduo de processá-la. Por outro lado, grande parte desta informação tem uma conexão muito tênue com o contexto de significados relevantes para o indivíduo, o que leva a que seja recebida mais como sujeira, ruído, nos termos da Teoria da Informação, que como ajuda para tomada de decisões ou a compreensão do mundo e suas circunstâncias.

Sem pretender reduzir o homem à dimensão cognitiva, desde esta perspectiva, poderia se dizer que um ser humano é um pólo de construção de significados. As diversas experiências, estímulos, informações e interação com seus semelhantes não só são processadas pelo indivíduo, mas, à medida que elas ganham sentido, significado, vão constituindo um de seus aspectos essenciais.

Este ser cognitivamente vivo, dinâmico, depende, para manter-se vivo, da forma em que se dá a interação com o ambiente informacional. A carência ou o excesso no fluxo da informação, sua qualidade, sua contextualização, e seu equilíbrio ou falta dele com os demais elementos que interagem com seu equilíbrio e sua homeostáse alteram sua saúde interior.

Esta metáfora deixa de sê-lo quando vemos a manifestação em âmbitos que nos são mais conhecidos destas doenças. Efetivamente, são cada vez maiores as evidências de doenças cardíacas, mentais, perda de memória, problemas de relacionamento, visuais etc., relacionadas a uma relação desequilibrada com a manipulação da informação.

O bombardeio televisivo, os panfletos no vidro do carro, as propagandas no correio, as mensagens eletrônicas solicitadas ou não -, as milhares de páginas disponíveis na Internet, os mecanismos de busca, revistas, livros, resenhas, memorandos, circulares são um desafio à sanidade mental de cada um de nós.

Exige-se de nós um "novo nascimento", em que reaprendamos a ignorar o que é irrelevante, a reparar no que é importante e, principalmente, a reagrupar, em novas unidades de sentido, os estímulos recebidos como informação.

Em outras palavras, o ambiente "informacional" se constitui em um novo meio, em que os estímulos não são mais estímulos primários, oriundos da natureza, mas unidades de significado que, entretanto, não necessariamente o tem para mim, até que não seja processado e eventualmente integrado mediante os novos instrumentos-habilidades a serem desenvolvidos.

Parte da resposta é "aprender a ignorar”, parte é identificar os pólos de significados em torno dos quais possam se reagrupar as informações que forem relevantes para nosso contexto.

Uma reação: As reações à avalanche informativa são inúmeras e diversificadas. Achei interessante a resposta de um grupo que se autodenomina "Luddites on-line". Atordoados pela avalanche de informações, milhares de ponteiros, figurinhas piscando, cores berrantes, marcos (frames) e janelas que se abrem e reproduzem fora de qualquer controle, o grupo criou um sítio ${ }^{12}$ interessante. As páginas foram produzidas com um visual simples e conteúdo organizado de forma a permitir, mais que a navegação, um descanso. Em resumo, é uma resposta concreta à necessidade de integrar harmoniosamente informação e vivência, tecnologia e mensagem - aparte a ironia do meio tecnológico utilizado para sua manifestação.

\section{MECANISMOS INTEGRATIVOS}

O acúmulo de conhecimentos, se bem agudizado em nossos tempos, não é fenômeno novo. Pode-se dizer, aos efeitos de raciocínio, que começa com o próprio surgimento da vida, que codifica nos seres vivos a experiência acumulada dos ancestrais. Esta codificação da experiência, do conhecimento, da informação, em genes, mitocôndrios e, em geral, em todos os mecanismos de reprodução que caracterizam um ser vivo, caracteriza não só um modo de transmissão de informação, mas também um processo de síntese. Não há um relato detalhado de todos os acontecimentos vividos pelos ancestrais, mas uma síntese do que seria relevante.

Esta associação entre os mecanismos característicos dos seres vivos e o processamento da informação trouxe para a área dos estudos cognitivos duas grandes contribuições vindas do campo da biologia. Por um lado, o estudo dos sistemas auto-organizativos, centrado nos trabalhos de Ilya Prigogine, por outro, os sistemas autopoiéticos, propostos por Humberto Maturana e Francisco Varela ${ }^{13}$.

A linguagem matemática, assim como se presta para a análise racional, incorpora também processos de síntese: as definições, que agrupam diversas entidades com diversas propriedades, em um conceito-síntese; os teoremas, que agrupam propriedades compartilhadas por classes de objetos, etc. 
Da mesma forma, as diversas ciências da natureza condensam em leis gerais observações e experiências particulares, assim como a análise dialética propõe uma fase de síntese.

Em resumo, a necessidade de síntese faz parte do processo cognitivo, tem sido atendida, de diversas formas nos diversos âmbitos, ao longo do tempo.

É interessante observar como, com a concentração de grandes esforços nos dois ou três últimos séculos, no paradigma racional, em paralelo, vai se fazendo cada vez mais manifesta a necessidade de visões alternativas.

Esta situação se faz particularmente clara no século XX, onde as grandes conquistas da ciência e da tecnologia são a conseqüência evidente desse esforço em larga escala, em uma direção definida: a "conquista" da natureza mediante a razão. "Domina-se" o átomo, o espaço e, mais recentemente, o código genético. É a era do racional por excelência, da dicotomia, de todo o potencial do método reducionista.

Simultaneamente, assim como os limites desta visão exigem a expansão dos referenciais nas ciências físicas, da mesma forma, os próprios referenciais cognitivos são expandidos em diversos sentidos e com diversas visões que vão além da tradicional busca de síntese e da resolução de dúvidas e conflitos encontrando "a verdade".

Referenciais integradores surgem de áreas tão diversas como a biologia, as ciências físicas, as tradições religiosas, as indagações místicas, a filosofia acadêmica e alternativa, configurando uma nuvem cujo caráter não claramente definido faz parte da própria visão que se esboça como alternativa. Este fluxo de idéias, por sua vez, interage alimentando-se de movimentos de reformulação de parâmetros de interação social, política e econômica, contribuindo para sua fertilização cruzada.

Uma das características em comum identificáveis nestes movimentos é uma visão integradora, na qual o que significa esta integração varia com cada formulação específica.

No contexto da identificação de contribuições para a construção da "ecologia da informação", destacam-se, em primeiro lugar, o chamado movimento holístico, provavelmente o mais indiferenciado, mas que, por outro lado, caracteriza uma visão alternativa à da fragmentação. As contribuições vindas da física incluem, desde as já clássicas, como relatividade, geral e restrita e o princípio da complementaridade, até visões mais "heréticas", como as relacionadas com as filosofias orientais (Fritjot Capra, por exemplo), o princípio da ordem implicada de David Bohm e o "paradigma holográfico" de Ken Wilber.

Na área da filosofia e epistemologia, mencionamos a seguir, brevemente, duas propostas que se complementam e que têm o potencial de contribuir para um redesenho do ambiente informacional que hoje se nos apresenta. A primeira é a visão transdisciplinar, a segunda, a reversibilidade.

\section{TRANSDISCIPLINARIDADE}

Uma das manifestações da fragmentação cognitiva é a divisão em áreas de conhecimento, cada uma com sua metodologia peculiar, seus ritos, estruturas de poder e valores; o que chamamos de disciplinas.

Esta divisão tem várias conseqüências, como a possibilidade de aprofundar em áreas de estudo muito específicas e desenvolver métodos muito afinados para investigar fenômenos de outra forma inacessíveis.

Por outro lado, dificulta o compartilhamento das descobertas, métodos e conceitos entre áreas diferentes, aliena a maioria das pessoas do acesso aos conhecimentos desenvolvidos, faz com que o desenvolvimento fragmentário do conhecimento possa levar a resultados contraditórios nas diferentes áreas, estabelece, enfim, uma barreira muito difícil de transpor no movimento de busca da síntese que se segue à análise.

O estudo de problemas complexos, que exige conhecimentos de várias áreas, tem levado à procura de formas de superar esta fragmentação cognitiva, a qual a realidade não tem por que respeitar. A primeira resposta é o enfoque multidisciplinar, em que especialistas de várias áreas se reúnem para aportar os conhecimentos específicos de suas disciplinas relevantes para o problema estudado. A dificuldade aqui é o diálogo entre especialistas, com linguagens, visões, propostas e conclusões diferentes.

Um segundo estágio de resposta tem consistido na formação de equipes com especialistas de diversas disciplinas, dispostos a trabalhar uma linguagem comum e abertos às propostas e modos de enfocar a realidade dos demais. É o enfoque interdisciplinar. Poderíamos dizer que, nele, o fator de integração é o problema. Ele permite uma reintegração dos resultados parciais em uma solução não fragmentada. Entretanto, do ponto de vista cognitivo, a pesquisa, a busca de soluções, ainda acontece na parcialidade de cada área. 
O desafio que se põe é como reconstituir a Humpty Dumpty, o lendário ovo da canção infantil, que, depois de cair do muro, não podia ser reconstituído nem por todos os cavaleiros do reino.

A solução que se põe é "o melhor é não quebrar o ovo". Esta resposta, aparentemente óbvia, põe seus desafios. Como conhecer um mundo complexo, desenvolver um conhecimento sofisticado, diversificado, sem a especialização? Como não fragmentar, se o próprio processo do conhecimento consiste em separar as coisas, os fenômenos por suas características, distinguir as ações que levam aos resultados desejados e as que têm o efeito contrário?

A proposta transdisciplinar surge na França, com Smoutz, e é trabalhada e difundida por outros, como Edgar Morin ${ }^{14}$ e seu grupo e, aqui no Brasil, por Pierre Weil e Ubiratan D’Ambrosio. Há diversas visões sobre esta proposta em construção. Eu resumiria minha visão da idéia no seguinte parágrafo.

Uma das formas de interpretar a transdisciplinaridade é como uma aproximação ao conhecimento que transcende as disciplinas. Não é pré-disciplinar, isto é, não se propõe a volta a um estágio "primitivo" do conhecimento, mas a uma visão integrativa que reconhece características específicas do fenômeno que interagem entre si. Outra forma de interpretá-la é como um corte transversal das disciplinas, em que todas são vistas desde dentro, mas integradas organicamente.

Eu prefiro a primeira visão, na qual eu colocaria um elemento que transcende a fragmentação cognitiva como o elemento integrador. Assim como na resposta interdisciplinar o fator aglutinador é o problema, na resposta transdisciplinar, o fator integrador é o ser humano, que não foi congnitivamente fragmentado, a quem não se disse "você não pode opinar porque não é da área".

\section{REVERSIBILIDADE}

Enquanto o holismo reflete uma disposição genérica a considerar as diversas manifestações do homem e do mundo de forma integrada, temos na proposta da "ordem implicada" de David Bohm ${ }^{15}$ a busca da explicitação das interações que acontecem entre fenômenos aparentemente diversos; já a visão autopoética oferece o paradigma dos sistemas orgânicos como padrão integrador em outras áreas de conhecimento.
A visão da reversibilidade, por sua vez, contribui com uma forma de superação da fragmentação dualista, não pela eliminação dos opostos numa visão indiferenciada, ou pela superação da síntese dialética, mas pelo trânsito dinâmico entre os aparentes extremos de uma mesma dimensão. Não se trata de uma simples análise de pontos positivos e negativos de uma alternativa, mas visão dos pólos como parte integral da questão, da dimensão analisada.

A idéia, ou a atitude, de reversibilidade, me chega especialmente através do trabalho realizado no Comitê Americano para a Investigação de Temas e Modelos com Perspectivas de Futuro, sob a coordenação do doutor Ramón P. Muñoz Soler. O Comitê integrava, na prática, e em suas reflexões, diversas dimensões da expressão humana, com propostas como as de Santiago Barbuy e Julia Saló (Mari), em Espaço para o Encontro Humano ${ }^{16}$, onde espírito, arte, arquitetura e ciência se encontram.

Nesse ambiente, a exploração da idéia de reversibilidade atendia desde às necessidades espirituais de unidade interior e com o cosmos - a dimensão original, desenvolvida pelo doutor $\mathrm{Muñoz}^{17}$ a partir dos ensinamentos recebidos de seu mestre, Don Santiago Bovisio -, expandindo-se para outras áreas como as ciências, onde, por exemplo, o desafio era a integração de uma interpretação da matéria como energia, ou como partícula, ou na área social, numa sociedade que, naquele momento, sofria uma guerra em que, obviamente, a oposição entre posições divergentes chegava ao extremo.

Neste contexto, a exploração do potencial da reversibilidade se me apresentou, em primeiro lugar, como uma alternativa vital, integrada por sua vez a uma visão de mundo e, portanto, a uma possibilidade de interpretação da realidade. A não determinação de uma visão entre alternativas aparentemente opostas significava, vitalmente, uma opção de liberdade. A idéia de reversibilidade dava a esta opção uma dimensão dinâmica.

O estudo dos movimentos cognitivos, desde os originários das ciências físicas, até os que respondem às necessidades mais íntimas do ser humano, passando pelas análises das ciências cognitivas, primeiro com Kuhn e depois, em mais detalhe, na área de inteligência artificial, levaram-me a perceber que havia implícita, em todas estas alternativas, uma dinâmica de busca de liberdade que poderia ser identificada com a idéia seminal de reversibilidade. 
Explorando a questão da transdisciplinaridade, concretamente em alguns grupos acadêmicos, surgia a questão de como se manter, na prática, a não divisão da interpretação da realidade em fragmentos cognitivos, sem, por outro lado, ter de deixar de observar, conhecer, reconhecer, distinguir todas atividades que implicam divisão. Neste contexto, a reversibilidade, como o trânsito entre polaridades, se nos apresentava como alternativa metodológica.

Não seria este o espaço para desenvolver em mais detalhe este tema, mas estimo que, como idéia-referência, pode servir como alternativa integradora, em um ambiente informacional em que o fluxo dos fragmentos parece inevitável, e a necessidade de manter uma unidade interior, individual, de significado, é não menos premente.

\section{INFORMAÇÃO PARA A INCLUSÃO SOCIAL}

Não queria concluir este rápido vôo sobre as dimensões menos lembradas do ambiente informacional, sem tocar na área social, através de um exemplo. A utilização da informação e das redes de comunicação nesta área não é nova e precede até à própria Internet. Entretanto, no ambiente atual, a direção das prioridades tem se invertido. Apresenta-se-nos, muitas vezes, um fenômeno que é inevitável, o crescimento do ambiente informacional, para o qual a sociedade tem de elaborar suas respostas em suas diversas áreas de interesse. Assim, fala-se em "impacto" das novas tecnologias, capacitação para o novo mercado e em alfabetização digital, dentre outras coisas.

No Brasil, uma convergência de interesses ligados à área das tecnologias da informação, com circunstâncias do governo federal, leva à proposta de um programa nacional de grande envergadura: o Programa Sociedade da Informação, com linhas de ação nas diversas áreas da sociedade nacional. Este programa se estrutura inicialmente com a elaboração de um Livro Verde, forma preliminar do programa, a ser discutido com a sociedade em geral, para ser depois consolidado num Livro Branco. Para a elaboração doLivro Verde, foram convocados diversos grupos de tzrabalho, um deles na área de educação.

Na opinião dos membros deste GT, a visão de educação contida na proposta original estava muito centrada em dois aspectos: capacitação para um novo mercado de trabalho e "alfabetização informática". Entendíamos que os objetivos da educação, principalmente se formulados dentro de um programa do governo que sem dúvida balizará políticas de desenvolvimento social, deviam ser mais abrangentes, tanto em sua concepção do ser humano, como em suas possibilidades de transformação social.
Foi assim proposta a inclusão de uma linha de ação chamada de "formação para a cidadania", em sintonia com sugestão similar, formulada independentemente por outros GTs, em particular o de Integração Regional, em proposta apresentada pelo recém-falecido Erno Pauliny.

Sem dúvida, a capacitação para a atuação no atual mercado de trabalho é fundamental para a inclusão social, da mesma forma que a "alfabetização informática". Há, entretanto, algumas objeções a nos limitarmos a esta visão.

Em primeiro lugar, mesmo reconhecendo o crescimento do ambiente informacional e de sua relevância na sociedade, não há por que se curvar em forma irrefletida a esta circunstância, tentando a ela se adequar a todo custo, sem questionar se a forma em que se manifesta atende aos anseios e necessidades mais essenciais dessa sociedade. Isto nos levou a nos perguntarmos, antes de mais nada, quais seriam os problemas mais prementes da sociedade, para só a partir daí pensarmos de que forma a educação poderia contribuir para sua solução, e se, de alguma maneira, as possibilidades oferecidas pelas atuais tecnologias de acesso à informação teriam algo a oferecer.

Sem dúvida, a atual situação de exclusão social é um dos maiores problemas em nosso país. Isto nos levou a trabalhar na identificação dos aspectos em que esta exclusão se manifesta e a desenhar propostas que, em sua mesma concepção, cultivassem aspectos como a criatividade, a participação ativa e a valorização, expressão e exposição de culturas locais. O outro aspecto é o acesso às tecnologias.

Há atualmente muitas análises sobre experiências realizadas com a introdução das novas tecnologias na educação, algumas mostrando que estas aumentam a exclusão, outras apontando o contrário. Daqui nossa preocupação no sentido de identificar a intencionalidade e a forma de aplicação das tecnologias, que podem ser includentes ou excludentes.

A outra dimensão que consideramos necessário ampliar é a que limita o ser humano à sua dimensão econômica, como desenvolvido anteriormente. Centralizar uma proposta de programa de governo no aspecto de capacitação para o mercado de trabalho nos pareceu uma redução não só das demais dimensões do indivíduo, mas inclusive das dimensões impactadas pelo atual ambiente informacional. 
Sem pretender detalhar aqui as propostas feitas, resumo as principais contribuições. Sendo a exclusão o grande problema social nacional, os passos necessários para a inclusão devem ser os principais em um programa deste tipo. Inclusão significa acesso físico à infra-estrutura, conexão em rede e computadores, significa capacitação para utilizar estes meios e significa, principalmente, a possibilidade de uma incorporação ativa no processo todo de produção, compartilhamento e criação cultural, os chamados "conteúdos".

A forma de se proporcionar este acesso deve estar integrada às condições locais existentes, em termos de suas organizações, tanto quanto em seus referenciais culturais. Centros de produção, criação e compartilhamento cultural (e de acesso à rede) devem estar integrados a associações comunitárias, centros religiosos, igrejas etc. E a produção cultural deve estar centrada nos valores significativos localmente, e não ser centralmente determinada, em um processo de aculturação mediado pela tecnologia.

\section{CONCLUSÃO}

O desenvolvimento de uma visão de mundo baseada na informação, visão esmiuçada da realidade, chega a seu clímax na constituição de um ambiente social identificado como "Sociedade da Informação".

As tecnologias e formas de organização e interação social dela derivadas oferecem elementos de grande valia para o ser humano, assim como produzem seus efeitos indesejados. A identificação destes efeitos exige uma postura crítica, como tem acontecido com outras tecnologias, para minimizá-los e propor respostas e alternativas.

O referencial cognitivo que conduziu a este ponto tem mostrado também suas limitações e falhas. Complementando a visão fragmentadora, referenciais integradores vêm se esboçando e estruturando. Mencionamos aqui alguns deles, especialmente a visão transdisciplinar e a metodologia da reversibilidade.

Finalmente, toda tecnologia, organização social e visão de mundo devem ser referenciadas no ser humano e suas necessidades, desde as mais essenciais até as mais sutis. A exploração dos novos potenciais oferecidos deve ser feita desde esta perspectiva, e não priorizando a necessidade de que o ser humano se adapte a uma mudança externa que lhe é imposta. A atenção aos valores humanos essenciais não só é possível, mas é necessária no desenho da utilização dos novos meios.

\section{REFERÊNCIAS BIBLIOGRÁFICAS}

1. MUÑOZ SOLER, Ramón Pascual. Antropologia de Síntesis. Ed. Depalma. 1980.

Universidad de Síntesis. Buenos Aires, 1984.

2. LAZARTE, Leonardo. Reversibilidade como metodologia da transdisciplinariedade. In: ENCONTRO com Capra. Brasília : [s. ed.], 1993.

3. UNIVERSIDADE DE BRASÍLIA. Núcleo de Estudos da Sociedade da Informação. Disponível em : www.socinfo.unb.br

4. SEMINÁRIO SOCIEDADE DA INFORMAÇÃO: PERSPECTIVA BRASILEIRA. Disponível em: www.socinfo.unb.br/seminário.

5. PROGRAMA SOCIEDADE DA INFORMAÇÃO. Disponível em: www.socinfo.org.br

6. UNIVERSIDADE DE BRASÍLIA. Programa Sociedade da Informação. Grupo Temático de Educação do Livro Verde. Disponível em: www.socinfo.unb.br/gt-edu.

7. MASUDA, Yoneji. A Sociedade da Informação - como sociedade pós-industrial. Rio de Janeiro : Ed. Rio, 1980.

8. DYSON, Esther. Release 1.0: informe financeiro sobre a Internet, de venda direta. [s. 1 : s. n.],1994.

9. LAZARTE, Leonardo. From knowledge to Wisdom: aI and beyond. London : Imperial College. Department of Computing, 1989. (Technical Report).

10. SHANNON, Claude E. A mathematical theory of communication. The Bell System Technical Journal, v. 27, n. 3, p. 379, 1948.

11. WIENER, Norbert. Cybernetics. [s. 1.] : MIT Press, 1948, 1961.???saber - duas datas?

12. LUDDITES on-line. Disponível em: www.luddites.com.

13. MATURANA, Humberto, VARELA, Francisco. Autopoiesis and cognition. [s. 1.] : D. Reidel, 1980.

14. MORIN, Edgar. Os sete saberes necessários para a educação do futuro. [s. 1.] : Unesco, 2000. 